\title{
THE PERFORMANCE OF NINE HUMAN HEARTS BEFORE, DURING, AND AFTER TRANSPLANTATION
}

\author{
W. A. WIELhorsKi, M.B., Ch.B., B. Patement, M.D., \\ I. DYrDA, M.D., F.R.C.P.(C), AND P. GRONDIN, M.D., F.R.C.s.(c) ${ }^{\circ}$
}

THE FOLLOWING is a report of our observations during the anaesthetic management of nine human heart allografts at the Montreal Heart Institute during the year 1968. The first five heart transplants in our hospital, performed between May and September 1968, were also the first five in Canada.

In spite of the increasing success of the operative technique and a rather benign immediate postoperative course, the long-term results were disappointing because of rejection of these homografts in seven out of nine cases. The incidence of rejection was high in spite of reasonably good histocompatibility. Tissue compatibility is vital for long-term survival of transplants. Viability of the transplanted heart is important in the immediate postoperative period. We wish to draw attention to some factors that could compromise viability and immediate post-transplant heart performance.

\section{Heart Damage Associated with Intracranial Lesions}

It has been reported that a significant number of patients with brain damage develop focal myocytolysis, a form of myocardial lesion. ${ }^{1}$

ECG changes could be demonstrated in animals six days after intracranial haemorrhage, ${ }^{3}$ and in men two days after such trauma. ${ }^{2}$ In cases of recovery from subarachnoid haemorrhage such ECG abnormalities returned to normal. ${ }^{2}$ This would suggest that the myocardial changes were reversible.

All our donors had extensive brain damage. Three of them, decerebrated for seven days, had ECG changes suspected to be of that origin. The changes consisted of broad inverted T-waves and prolonged Q-T intervals. As they were not specific, other factors, e.g. acid-base imbalance and electrolyte abnormalities, had to be considered as a possible cause.

One donor was not accepted but two were (cases no. 5 and 9, Table I). The ECG abnormalities disappeared 24 to 36 hours after transplantation, and the hearts performed very well for 119 and 106 days before the onset of rejection and infection.

\section{Hypotensive and Hypertensive Episodes of the Donors}

Our donors, like most head-injury patients, required vasopressors to maintain the blood pressure even in the absence of hypovolaemia (Table I).

Donors no. 1 and no. 9 had been on epinephrine infusion for a long time.

"Division of Anaesthesia, Department of Surgery, Montreal Heart Institute. 

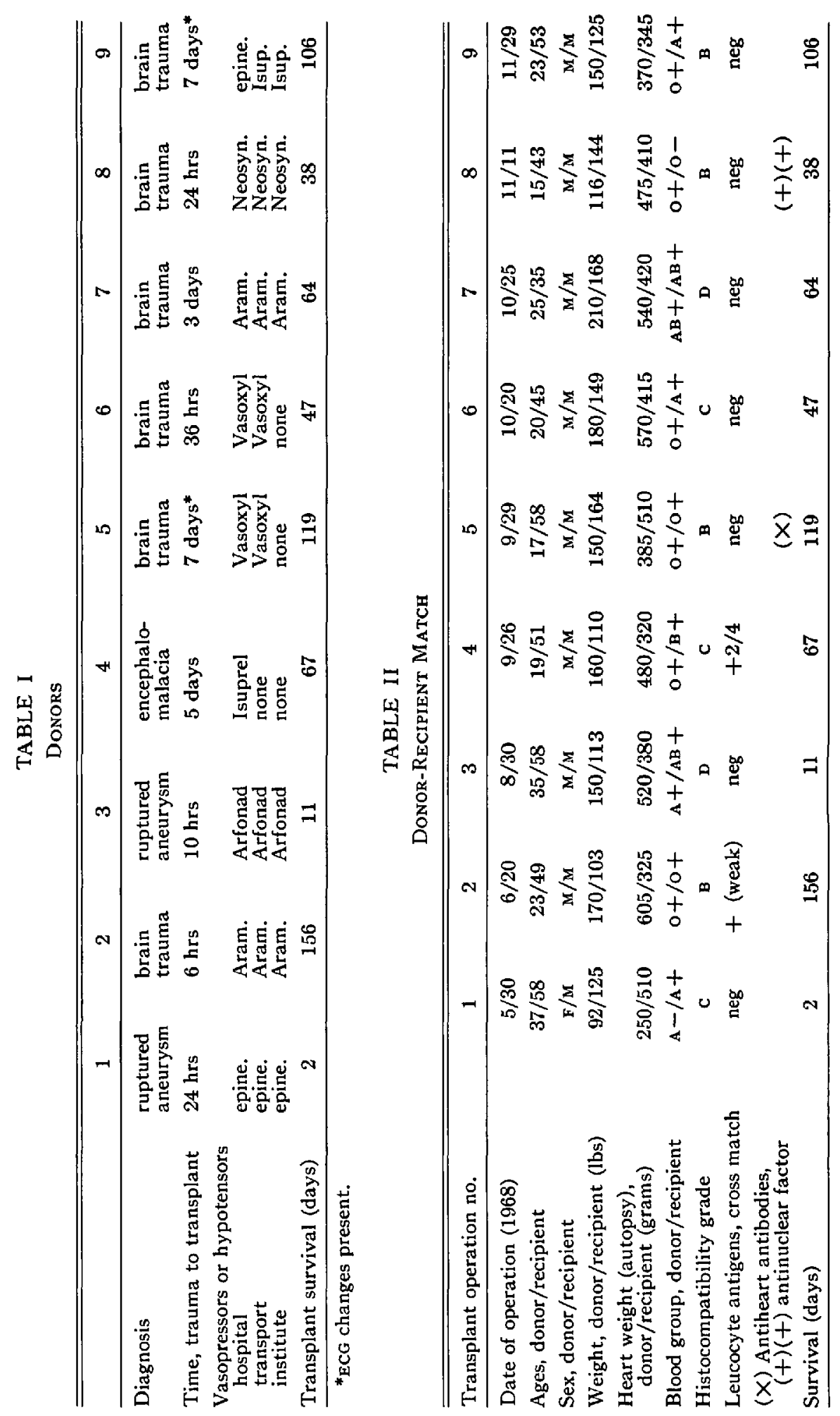
This in itself might have had a damaging effect on the myocardium, as reported by Hockman et al. ${ }^{12}$

One donor (no. 3) had severe hypertension due to polycystic kidneys. His blood pressure had to be controlled by trimetaphan (Arfonad) infusion. This heart performed very well when implanted in a very poor risk recipient who needed reoperation on the second postoperative day for resection of an aneurysm of the abdominal aorta and of both iliac arteries. He underwent a bilateral aortofemoral graft. During the five-hour operation, his new heart maintained a very stable blood pressure. The pulse rate did not vary more than $10-20$ beats per minute from the usual steady rhythm of 80 to 90 beats so characteristic of denervated hearts (Fig. 1). This patient recovered well from his second operation but died on the eleventh day from acute rejection and intracranial haemorrhage. The histocompatibility in this case was the poorest in our series - a D match (Table II).

\section{Hypotension during the Transfen}

Two hypotensive episodes occurred during the transfer of donors in the ambulance and needed active treatment. It is worth mentioning that one cannot run an intravenous drip properly from a bottle in an ambulance. There is not enough head room for gravity to be used. Consequently, medication had to be given by injection. Blood transfusion could be kept running only by using a Fenwall pressure infusor. Further, there is not enough space in the ambulance on each side of the patient for two attendants to carry out controlled respiration and

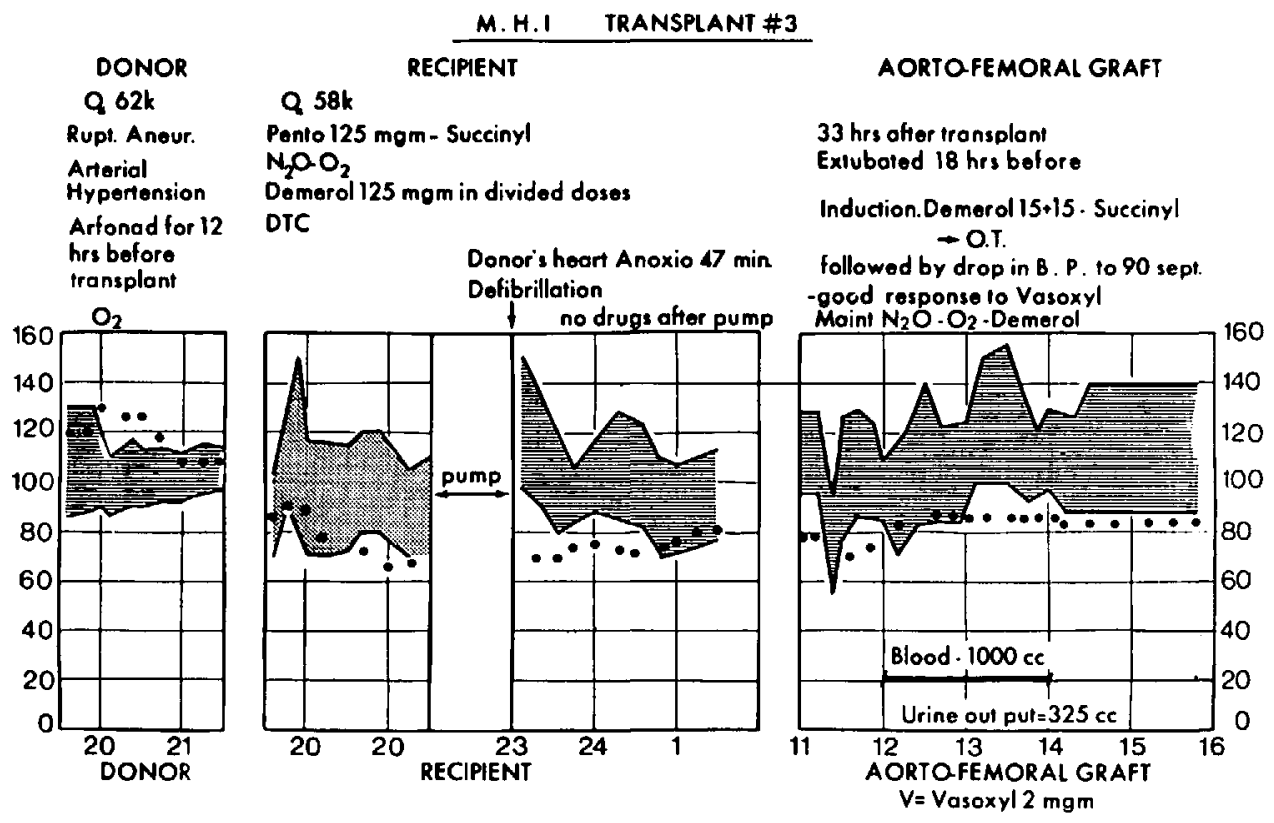

Figure 1. Anaesthetic charts of case no. 3. The second operation after the heart transplant was very well supported by the "new" implanted heart. 
external cardiac massage, if required. A timely report by the National Research Council (U.S.A.) suggests changes in the design of ambulances, which should have more head room than the current hearse or station-wagon models. ${ }^{4}$

One donor was transported by airplane from New Brunswick and there were no such difficulties in maintaining a stable circulation during the flight. For controlled respiration we used "Hope" - a self-inflating bag attached to an oxygen cylinder.

\section{Chest InjuRy and Lung Infection}

Three donors involved in traffic accidents also had chest injuries. One had a retrosternal haematoma (no. 2). One had haemothorax and haemopericardium (no. 4), and one had lung trauma with haemo-pneumothorax (no. 6).

Donor no. 5 had been unconscious and tracheostomized for seven days. He developed advanced bronchopneumonia, and pus was present around the tracheostomy wound. None of these potentially dangerous situations compromised the transplanted hearts. Patients who received hearts from donors 2 and 5 were actually the longest survivors with the best postoperative evolution (Table III).

Five out of nine donors' hearts were resuscitated from cardiac arrest, two of them twice. They were subjected to external cardiac massage; one had intracardiac epinephrine injection 20 hours before being transplanted, and this resulted in haemopericardium. (Table'III).

\section{Donors' Heart Function during the Operation}

While an independent team of neurologists confirmed the diagnosis of brain death, the donors' cardiovascular systems were stabilized. Acid-base balance, electrolytes, central venous pressure, and urinary output were brought to near normal values. The blood pressure was at acceptable levels in all cases at the start of the operation. However, during the sternotomy, donors 1 and 6 developed ventricular fibrillation for no obvious reason. Both responded to D.C. countershock. Sinus rhythm and good blood pressure were restored.

In case 1 the donor's heart was removed in normothermia as soon as it stopped beating, which it did when the respirator support was discontinued. The poor postoperative performance of this heart made us change our technique. In all other cases the donors were cooled to between $17^{\circ}$ and $29^{\circ} \mathrm{C}$ by extracorporeal perfusion before the hearts were removed.

We used a Sarns pump with a heat exchanger and disposable Travenol bubble oxygenator, primed with 5 per cent dextrose in one-half normal saline, with added potassium, heparin, and sodium bicarbonate. Carbon dioxide was added to the oxygen to prevent respiratory alkalosis. ${ }^{14}$

A modified transplantation technique of Lower and Shumway was employed. ${ }^{11}$ The right atrium was opened in a way that avoided damage to the conduction pathways between the sinus and the A-v node. All four auricular appendages were removed. The recipient's heart was resected by division of the atria, aorta, and the pulmonary artery, followed by orthotopic re-anastomosis of the donor's heart (Fig. 2). 


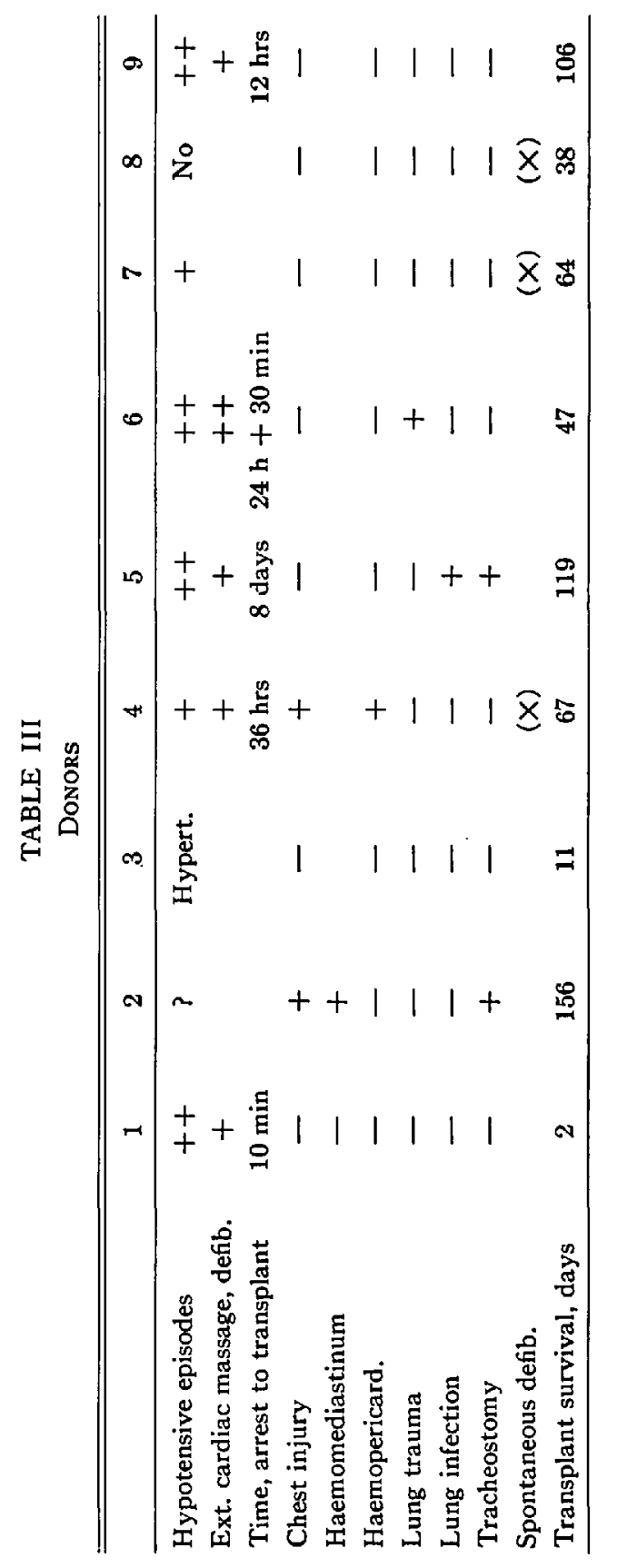




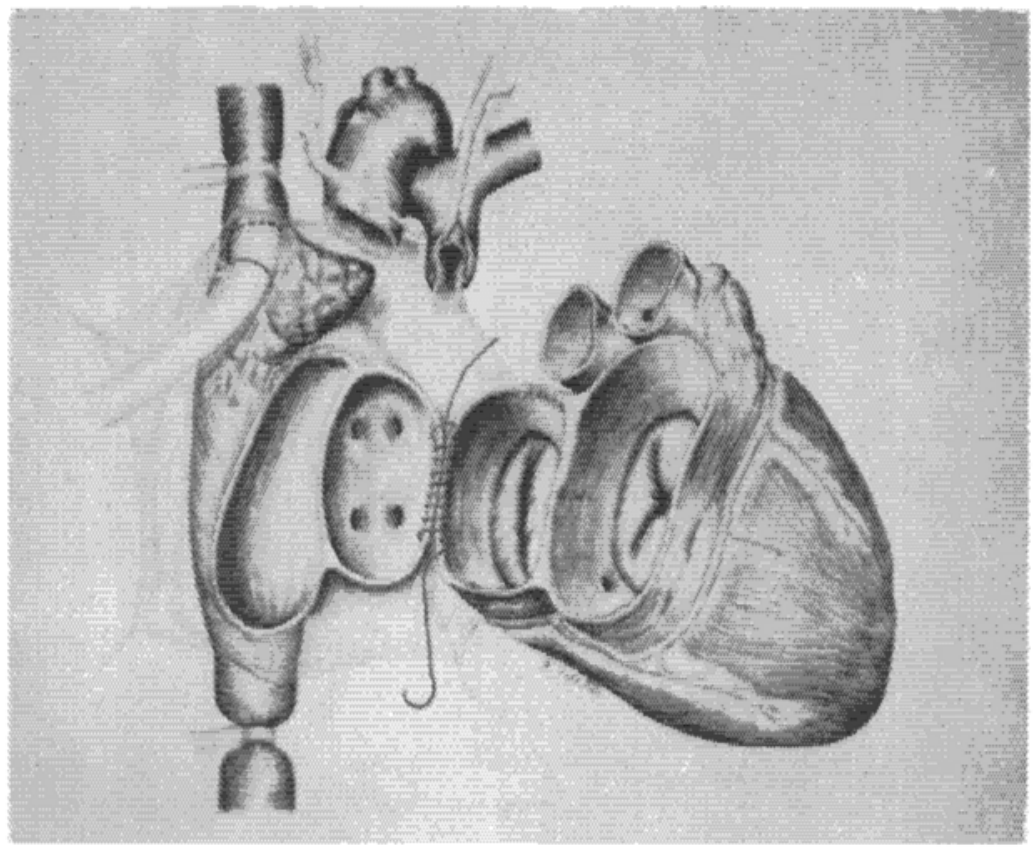

Froune 2. Heart transplant technique of orthotopic re-anastomosis of the donor's heart.

This involved two periods of anoxia for the donor's heart. The first anoxic episode started when the donor's aorta was cross-clamped, and lasted until both atria were anastomosed. This extended from 38 to 53 minutes.

Then the donor's heart was perfused through the aortic stump with blood from the pump at a temperature of $28^{\circ}$ to $35^{\circ} \mathrm{C}$. This perfusion lasted 12 to 20 minutes, during which pulmonary artery suture was carried out. Thus these hearts were able to recover partially from the first anoxic episode before the second and much shorter period af anoxia took place during the suture of the aorta.

Aortic anastomosis took 9 to 23 minutes, without coronary perfusion. (Table IV). With the heart implanted in the recipient's chest, the temperature was raised to $37^{\circ} \mathrm{C}$. While the patients remained on full bypass, air was aspirated and the root of the aorta unclamped. Spontaneous defibrillation occurred in three cases and D.C. countershock was used in six to restore sinus rhythm.

Stress by the news media on the occurrence of spontaneous auricular rhythm seemed to be unwarranted, as in our experience this did not relate to the preoperative condition of the donor's heart, the duration of peroperative anoxic periods, or the length of postoperative survival (Table IV).

\section{Postoperative Performance of the Hearts}

In all cases except no. 9 digitalization was started after the bypass and continued during the whole postoperative period. It was known from animal 
TABLE IV

Periods of ANoxia of the Donors' Hearts

\begin{tabular}{lrrrrrrrrr}
\hline \hline & \multicolumn{10}{c}{ Patient no./days lived } \\
\cline { 2 - 10 } & $1 / 2$ & $2 / 156$ & $3 / 11$ & $4 / 67$ & $5 / 119$ & $6 / 47$ & $7 / 64$ & $8 / 38$ & $9 / 106$ \\
\hline 1st anoxia, min & 38 & 53 & 47 & 48 & 46 & 48 & 51 & 42 & 45 \\
Temperature, ${ }^{\circ} \mathrm{C}$ & $?$ & 24 & 26 & 26 & 24 & 29 & 27 & 17 & 25 \\
Coronary perfusion, min. & 19 & 36 & 17 & 12 & 19 & 21 & 28 & 23 & 25 \\
$\begin{array}{l}\text { cc/min flow } \\
\text { Temperature, }{ }^{\circ} \mathrm{C}\end{array}$ & 300 & 400 & 300 & 400 & 500 & 600 & 500 & 600 & 500 \\
$\begin{array}{l}\text { Second anoxia, min. } \\
\quad \text { (aortic suture) }\end{array}$ & 35 & 29 & 28 & 29 & 29 & 29 & 28 & 30 & 30 \\
Spontaneous defibrillation & 16 & 10 & 9 & 10 & 17 & 8 & 20 & 11 & 9 \\
\hline
\end{tabular}

experiments that the denervated hearts develop congestive heart failure and need digitalization.

We did not experience the repeated episodes of progressive hypotension after the cardio-pulmonary bypass, as reported by Keats et al. in ten cases. ${ }^{5}$ The only differences between our two techniques are that, first, they do not perfuse the donor, and second, their operation is carried out at normothermia and without coronary perfusion.

Neither did we see the rapid heart rates after defibrillation described by the same group ( Table V). In case no. 1 the cardiac output was low and the patient had persistent bradycardia. Isoproterenol infusion and later a pacemaker were used. This patient received a small and poor-quality heart, which had suffered many anoxic episodes previously and was unable to take the full load of the circulation. Circulation was intermittently assisted by partial bypass for two days.

In case no. 9 the surgeons felt that the line of incision in the donor's right atrium might have affected the preferential conduction pathways between the sinus and the A-v nodes. This patient had junctional bradycardia which responded well to isoproterenol. He lived 106 days and his slow heart rate persisted till the end. He died of a cerebro-vascular accident and had bilateral pulmonary infection.

\section{Denervation}

Autotransplants of animal hearts can be studied without the complicating factors of rejection and immunosuppression. They have demonstrated that such hearts are soon depleted of catecholamines, ${ }^{6}$ develop congestive heart failure, have altered glucose metabolism ${ }^{7}$ and respond well to digitalization. ${ }^{8}$ The importance of an intact:adrenergic system in patients with congestive heart failure has been well documented by Gaffney and Braunwald. ${ }^{8}$

On the basis of all previously accumulated evidence, we anticipated the occurrence of congestive heart failure after the transplantation and we digitalized all our patients and later kept them on maintenance doses of cardiac glycosides and diuretics, with the exception of patient no. 9. They all responded well to Digitalis. 


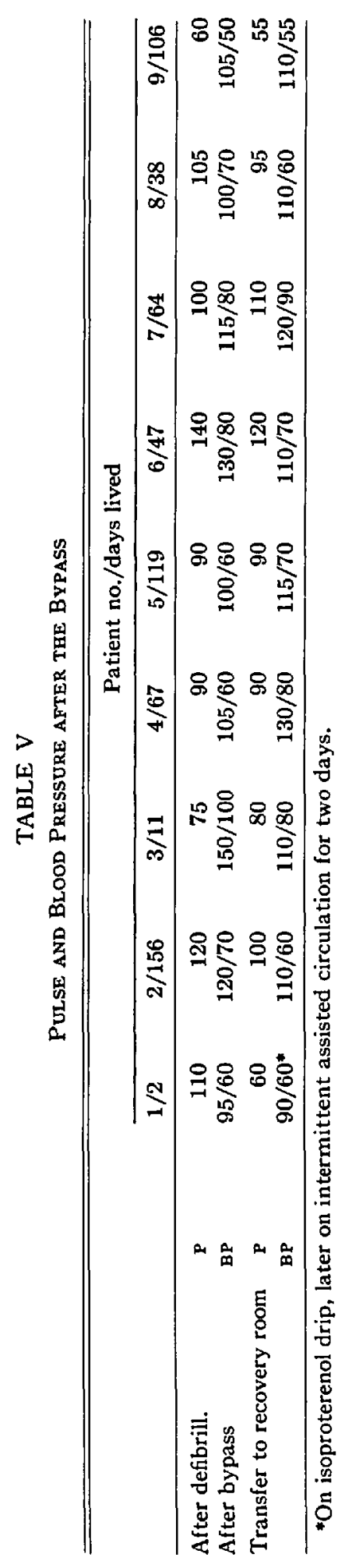


The responses of denervated hearts to some other drugs are altered. They follow Cannon's law of denervated structures, ${ }^{10}$ with supersensitivity to catecholamines which have a "direct" action - like epinephrine, norepinephrine, and isoproterenol - and diminished sensitivity to drugs with "indirect" cardiac action, depending on local stores of norepinephrine. These drugs include ephedrine, mephentermine (Wyamine), and metaraminol (Aramine).

In case no. 3 we noticed in the second postoperative week that the patient did not respond to an increased dosage of metaraminol, but responded briskly to very slow isoproterenol infusion.

Also, as anticipated, atropine injections did not alter the heart rate after transplantation.

\section{Postoperative Cardiac Output}

Postoperative cardiac output studies in case no. 8 revealed a satisfactory cardiac index of $3.4 \mathrm{~L} / \mathrm{min} / \mathrm{m}^{2}$ nine hours after the operation. In case no. 9 the cardiac index was at $2.57 \mathrm{~L} / \mathrm{min} / \mathrm{m}^{2}$ two hours after the operation and rose to $4.0 \mathrm{~L} / \mathrm{min} / \mathrm{m}^{2}$ in the next eight hours. These data seemed to confirm the clinical assessment of good myocardial performance seen in the postoperative period.

Haemodynamic studies performed in five patients, at a stage when there was evidence of cardiac rejection, showed left ventricular dysfunction (Campeau et $\left.a .^{13}\right)$.

\section{Conclusions}

In our experience with anaesthetic management of nine human heart allografts observations were made which may be of some significance. The donor heart's ECG changes associated with intracranial lesions disappeared within two days after transplantation. In all but one case postoperative evolution did not seem affected by the donor's hypotension, cardiac arrests, chest injuries, and the prolonged use of vasopressors. Moderately hypothermic perfusion of donors by an extracorporeal circulation and perfusion of the coronaries at one stage of the transplantation seems to protect the donor hearts and is beneficial for the immediate post-transplantation performance.

\section{SUMMARY}

The operative and postoperative performance of nine transplanted human hearts is outlined. Immediate cardiac action was excellent in all but one case. Attention is drawn to several factors which can affect the performance of these hearts before and during cardiac transplantation.

\section{RÉSUMÉ}

Ce travail rapporte quelques observations faites au cours de neuf transplantations cardiaques. Les anomalies électrocardiographiques observées chez certains 
des donneurs et attribuées au dommage cérébral ont complètement disparu après la transplantation.

Dans notre série, l'évolution postopératoire immédiate de même que la survie des malades n'ont pas semblé reliées aux épisodes d'hypotension, aux arrêts cardiaques ni aux traumatismes thoraciques survenus chez les donneurs.

Sauf dans notre premier cas, l'usage prolongé de vasopresseurs chez les donneurs n'a pas semblé avoir d'influence sur l'état de la circulation observée après transplantation.

La protection du myocarde transplanté par l'hypothermie (prélèvement sous circulation extra-corporelle hypothermique, refroidissement par du sérum froid et perfusion des coronaires durant une partie de la greffe), nous semble un facteur important pour obtenir une bonne circulation dès la fin de la greffe.

\section{REFERENCES}

1. Convon, R. C. R. Heart Damage Associated with Intracranial Lesions. Brit. Med. J. 3: 29 (1968).

2. Hoffrerand, B. I. \& Morgan, B. D. G. Functional Significance of Electrocardiographic Changes Associated with Subarachnoid Haemorrhage. Lancet. i: 844 (1965).

3. Burch, G. E.; Sun, S. C.; Colcolough, H. L.; de Pasquale; N. P.; \& Sohal, R. S. Acute Myocardial Lesions, following Experimentally Induced Intracranial Haemorrhage in Mice. Arch. Pathol. 84: 517 (1967).

4. National Research Council. The Ideal Ambulance. J.A.M.A. 207: 672 (1969).

5. Keats, A. S.; Strong, M. J.; Grrgis, K. Z.; \& Goldstein, A. Observations during Anesthesia for Cardiac Homotransplantation in Ten Patients. Anesthesiology. 30: 192 (1969).

6. Cooper, T.; Willman, V. L.; Jellinek, M.; \& Hanlon, C. R. Heart Autotransplantation: Effect on Myocardial Catecholamine and Histamine. Science. 138: 40 (1962).

7. Willaman, V. L.; Cooper, T.; Cian, L. G.; \& Hanlon, C. R. Mechanism of Cardiac Failure after Excision and Reimplantation of the Canine Heart. Surg. Forum. 13: 93 (1962).

8. Cooper, T.; WiLlman, V. L.; \& HanLon, C. R. Drug Responses of the Transplanted Heart. Dis. Chest. 45: 284 (1964).

9. GafFney, T. E. \& Braunwald, E. Importance of the Adrenergic Nervous System in the Support of Circulatory Function in Patients with Congestive Heart Failure. Am. J. Med. 34: 320 (1963).

10. Cannon, W. B. \& Rosenblueth, A. The Supersensitivity of Denervated Structures: A Law of Denervation. New York: Macmillan (1949).

11. Lower, R. R.; StofFer, R. G.; \& ShUMWAY, N. E. Homovital Transplantation of the Heart. J. Thorac. \& Cardiovasc. Surg. 41: 196 (1961).

12. Hockman, C. H.; ManUCK, H. P.; \& HoFF, E. C. E.c.G. changes resulting from cerebral stimulation: II. A Spectrum of Ventricular Arrhythmias of Sympathetic Origin. Am. Heart J. 71: 695 (1966).

13. Campeau, L.; Pospisi, L.; Grondin, P.; Dyrda, I.; \& LePage, G. Cardiac Catheterization Findings at Rest and after Exercise in Patients Following Cardiac Transplantation. Am. J. Cardiol. (In press).

14. Paiement, B.; Wielhorsk, W. A.; Grondin, P.; Lepage, G.; \& Dyrda, I. Anaesthesia for Heart Transplants. Laval Med. (in press). 